\title{
Spectrum of HRCT findings among asymptomatic and recovered COVID-19 patients: how did they impact the clinical decision?
}

\author{
Ahmed Samir ${ }^{1 *}$ D, Mohamed Saied Abdelgawad ${ }^{2}$ (D) Ayman Ibrahim Baess ${ }^{3}$ (D) and \\ Hebatallah Hassan Mamdouh Hassan ${ }^{1}$ (i)
}

\begin{abstract}
Background: Decisions about asymptomatic COVID-19 patients are always critical, either during initial screening or during recovery. Spread of infection will be inevitable if those patients were left non-isolated. This study aimed not only to survey spectrum of HRCT findings of COVID-19 among asymptomatic and recovered patients but also to record unexpected results and document their impact upon the clinical decision.

Results: The study was retrospectively conducted, during June and July 2020, on 120 patients proved with COVID19, during initial HRCT screening or delayed following announcement of recovery. All patients were completely asymptomatic. They included 72 males and 48 females (60\%:40\%). Their age ranged from 10 to 58 years (mean $35.95 \pm 12.25$ SD). HRCT was analyzed by three expert consultant radiologists in consensus. Among asymptomatic initially screened COVID-19 patients, additional to GGOs, bilateral consolidative changes were unexpectedly found together with secondary fibrosis (23.3\% and 10\%). HRCT results significantly impacted the clinical decision $(P<$ 0.0001); PCR had to be repeated with home isolation (43.3\%). Infected health care providers had to stop their duty immediately (20\%). Isolated hospitalization replaced routine ward admission (25\%). Cautious surgical interference was performed using full personal protective equipment (PPE) (8.3\%). Among asymptomatic recovered COVID-19 patients, unexpected large lesions (> $3 \mathrm{~cm}$ ) were found $(70 \%)$. Near $50 \%$ of lung volume was persistently affected (10\%). Secondary fibrosis was striking (33\%). Encysted hydro-pneumothorax persisted for a whole month (1.7\%). "No-isolation" decision remained unchanged because of clinical and laboratory stability; however, steroids were prescribed to speed lung recovery.
\end{abstract}

Conclusion: HRCT findings among asymptomatic and recovered COVID-19 patients can be unexpected and can definitely impact the clinical decision.

Keywords: COVID-19, Asymptomatic, HRCT, Clinical, Decision

\footnotetext{
* Correspondence: Sweetjomana36@hotmail.com

'Department of Radiodiagnosis and Intervention, Faculty of Medicine,

University of Alexandria, 17 Champollion Street, El-Messalah, Al-Kartoom

Square, Al-Azareta, Alexandria 21526, Egypt

Full list of author information is available at the end of the article
}

\section{Springer Open}

( ) The Author(s). 2020 Open Access This article is licensed under a Creative Commons Attribution 4.0 International License, which permits use, sharing, adaptation, distribution and reproduction in any medium or format, as long as you give appropriate credit to the original author(s) and the source, provide a link to the Creative Commons licence, and indicate if changes were made. The images or other third party material in this article are included in the article's Creative Commons licence, unless indicated otherwise in a credit line to the material. If material is not included in the article's Creative Commons licence and your intended use is not permitted by statutory regulation or exceeds the permitted use, you will need to obtain permission directly from the copyright holder. To view a copy of this licence, visit http://creativecommons.org/licenses/by/4.0/. 


\section{Background}

COVID-19 is a highly infectious disease that started in Wuhan in December 2019 and rapidly spread all over the world to be announced as a pandemic by the WHO in March 2020. Infection can be transmitted through respiratory air droplets or via direct contact with contaminated surfaces [1-4].

While COVID-19 is mainly manifested by fever, cough, dyspnea, and chest tightness, it was reported that around $1-5 \%$ of patients can be asymptomatic. Those asymptomatic patients are recommended to be isolated to avoid further spread of infection [5-7]. Patients are announced to be recovered from the disease and discharged from the hospital when they have two consecutive negative PCR swab tests at least $24 \mathrm{~h}$ apart. Those patients are mostly asymptomatic [8].

Decisions about asymptomatic and recovered patients are always critical. They need to be highly accurate and also rapid because infection spread will be inevitable if those patients were left non-isolated. Considering the PCR low sensitivity, time consumption, high cost as well as non-availability in some countries, HRCT screening has expanded to involve not only those persons who had contact with proved COVID-19 patients but also every patient who will be admitted to a health facility to receive any kind of medical care. This study aims to record unexpected HRCT findings among asymptomatic and recovered COVID-19 patients, also to evaluate their impact upon clinical decision.

\section{Methods}

\section{Study population and medical records review}

This study was retrospectively conducted, during June and July 2020, on 120 patients proved with COVID-19; 60 patients were discovered during initial HRCT screening while other 60 patients had delayed abnormal CT findings for 2 to 4 weeks following announcement of recovery. All patients were completely asymptomatic. They included 72 males and 48 females (60\%:40\%). Their age ranged from 10 to 58 years (mean age was $35.95 \pm 12.25 \mathrm{SD}$ ).

The study was approved by The Ethics Committee of our University Hospital. Patient consent was waived by the Research Ethics Board with assurance of respect of confidentiality of the patients and medical records.

Inclusion criteria were completely asymptomatic patients with positive HRCT results during one of the following scenarios: (1) Initial HRCT screening for asymptomatic patients with recent contact history with proved COVID-19 patients or asymptomatic patient with other irrelevant medical condition necessitating hospital admission (both proved positive for COVID-19 using PCR swab tests earlier or later). (2) Follow-up CT scans for asymptomatic recovered COVID-19 patients, performed 2-4 weeks after two consecutive negative PCR results announcing patient recovery.

Exclusion criteria were (1) degraded CT scans quality because of respiratory motion artifacts. (2) Any chest symptom relevant to COVID-19.

Evaluation of the impact of HRCT results on the clinical decision was done by a single consultant pulmonologist who has 19 years' experience in the field of infectious lung diseases. Additional correlation with the oxygen saturation and laboratory tests among the recovered patients was also performed.

\section{CT scanning and parameters}

Two MDCT machines were used: Siemens SOMATOM Sensation 64 (Germany) and Toshiba Aquilion CXL/CX 128 (USA). The following CT scanning parameters were used: $1 \mathrm{~mm}$ slice thickness, $1 \mathrm{~mm}$ detector collimation, 0.6-0.9 s tube rotation, helical mode volumetric HRCT with $100-120 \mathrm{kVp}$ and $80-200 \mathrm{~mA}$, according to the weight of patients and clinical indication. Intra-venous contrast administration was not used.

\section{CT analysis}

CT scans were evaluated in consensus by three consultant radiologists who were informed with the clinical data and have 15, 19, and 25 years of experience in chest imaging. Multi-planner reconstruction (MPR) was used for image analysis. Post-processing maximum intensity projection (MIP) and minimum intensity projection (MinIP) reconstructions were performed. Each CT scan was evaluated according to (1) site of lung involvement, (2) universally agreed CT findings with COVID-19 including ground-glass opacities (GGO) with or without consolidative changes in addition to special signs such as "Atoll sign" and "Crazy paving pattern" [3], manifestations of bronchial or pleural involvement.

\section{Statistical analysis}

The prevalence rate of HRCT findings was estimated as the percentage of patients showing any criterion. Data were compared using a chi-square test and $P$ value < 0.05 was considered statistically significant. Online calculators were used (https://www.socscistatistics.com/).

\section{Results}

Wide spectrum of HRCT findings were found in this study among both asymptomatic initially screened patients and asymptomatic recovered patients. They included unexpected results regarding the number, the size of the lesions, the site and extension of lung involvement, and the different morphological CT features. All HRCT findings are detailed in Table 1. 
Table 1 Distribution of patients according to "Prevalence of HRCT findings"

\begin{tabular}{|c|c|c|c|c|}
\hline \multirow[t]{3}{*}{ Prevalence of HRCT findings } & \multicolumn{4}{|c|}{ Asymptomatic COVID-19 patients } \\
\hline & \multicolumn{2}{|c|}{ Initially screened } & \multicolumn{2}{|c|}{ Recovered } \\
\hline & $N(60)$ & $\%$ & $N(60)$ & $\%$ \\
\hline \multicolumn{5}{|l|}{ * Unilateral versus bilateral lung involvement } \\
\hline Unilateral (one lung involved) & 18 & $30 \%$ & \multicolumn{2}{|c|}{ Not detected } \\
\hline Bilateral (both lungs involved) & 42 & $70 \%$ & 60 & $100 \%$ \\
\hline \multicolumn{5}{|l|}{ * Size and extension of the lesions } \\
\hline Less than $3 \mathrm{~cm}$ & 42 & $70 \%$ & 10 & $16.7 \%$ \\
\hline $\begin{array}{l}\text { Peripheral ( }>3 \mathrm{~cm} \text { longest dimension but }<3 \mathrm{~cm} \text { extension } \\
\text { from pleural surface). }\end{array}$ & 15 & $25 \%$ & 42 & $70 \%$ \\
\hline $\begin{array}{l}\text { Peripheral ( }>3 \mathrm{~cm} \text { extension from pleural surface but }<50 \% \text { of lobar } \\
\text { involvement) or peri-bronchial }(>3 \mathrm{~cm})\end{array}$ & 3 & $5 \%$ & 6 & $10 \%$ \\
\hline $\begin{array}{l}\text { Diffuse lobular pattern (extending proximally }>3 \mathrm{~cm} \text { from pleural } \\
\text { surface and }>50 \% \text { of lobar involvement) }\end{array}$ & \multicolumn{2}{|c|}{ Not detected } & 2 & $3.3 \%$ \\
\hline \multicolumn{5}{|l|}{ * Number of the lesions (excluding diffuse lobar pattern) } \\
\hline Less than 3 & 24 & $40 \%$ & \multicolumn{2}{|c|}{ Not found } \\
\hline More than 3 & 36 & $60 \%$ & 60 & $100 \%$ \\
\hline \multicolumn{5}{|l|}{ * HRCT findings } \\
\hline X GGO nodules or patches & 46 & $76.7 \%$ & 36 & $60 \%$ \\
\hline "Atoll sign" (starting organization) & 6 & $10 \%$ & 24 & $40 \%$ \\
\hline "Air bubble sign" & 1 & $1.7 \%$ & 4 & $6.7 \%$ \\
\hline Secondary fibrosis & 6 & $10 \%$ & 20 & $33.3 \%$ \\
\hline "Crazy paving pattern" & 6 & $10 \%$ & \multicolumn{2}{|c|}{ Not found } \\
\hline X GGOs mixed with consolidative changes & 14 & $23.3 \%$ & 24 & $40 \%$ \\
\hline "Curvilinear" consolidations or fibro-consolidations & 2 & $3.3 \%$ & 24 & $40 \%$ \\
\hline \multicolumn{5}{|l|}{ * Associated signs/findings } \\
\hline Hydro-pneumothorax & \multicolumn{2}{|c|}{ Not detected } & 1 & $1.7 \%$ \\
\hline Bronchial wall thickening and traction bronchiectasis & \multicolumn{2}{|c|}{ Not detected } & 1 & $1.7 \%$ \\
\hline
\end{tabular}

* Highest values are demonestrated in italic

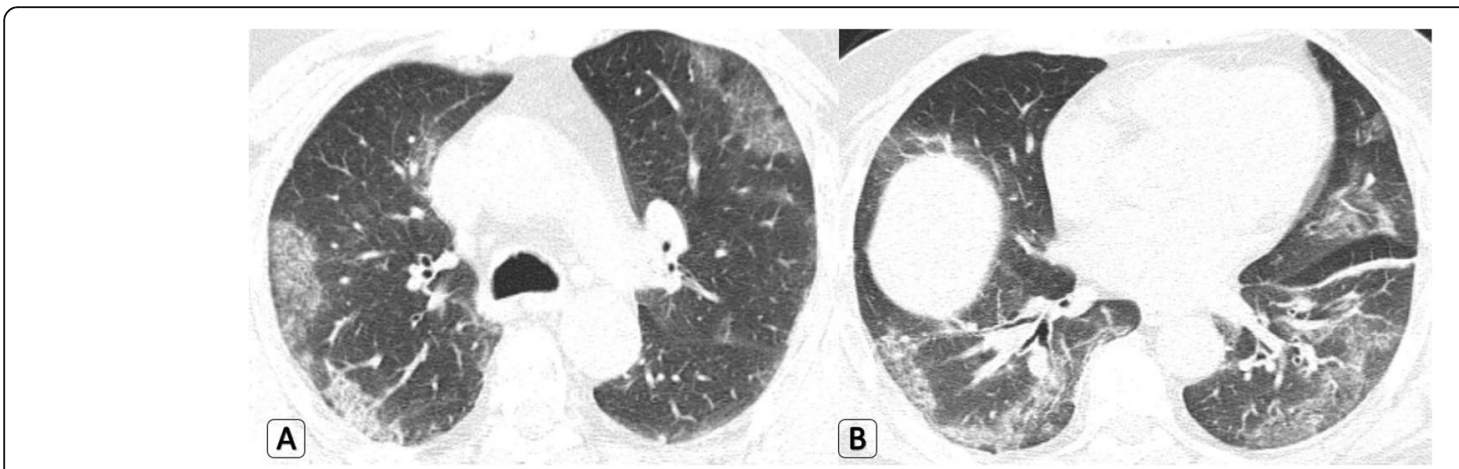

Fig. 1 A 45-year-old male patient who had positive contact history with recently proved COVID-19 patient and was completely asymptomatic. a-b Axial HRCT chest lung window showed bilateral large peripheral located ground-glass patches with mild septal thickening (evolving crazy paving pattern) and left basal fine atelectatic band. Clinical decision was home isolation, medical treatment, and PCR testing. Positive PCR result for COVID-19 was proved later 
Regarding the asymptomatic patients with positive initial HRCT screening

\section{$P C R$ results and clinical course}

Timing of positive PCR results was variable; only 31/60 patients $(51.7 \%)$ had positive PCR swab results at the first trial while 17 patients $(28.3 \%)$ had positive results at the second trial and the remaining 12 patients (20\%) had late positive results at the third trial.

Forty-two patients had their initial PCR swab tests before HRCT screening; 26 patients among them had negative PCR results, and then proved to be positive later (2-4 days) after HRCT screening. Other three patients, who were admitted for non-pulmonary medical conditions and performed HRCT screening, showed negative first PCR results then proved to be positive later.

All patients were persistently asymptomatic till the PCR proof of COVID-19 infection.

\section{HRCT findings}

Bilateral lung involvement was predominant in 42/60 (70\% of patients), the number of lesions exceeded three in $36 / 60(60 \%$ of patients) and the size of lesions exceeded $3 \mathrm{~cm}$ in 18/60 (30\% of patients) (Fig. 1).

In addition to GGOs, consolidative changes were found in $18 / 60$ (23.3\% of patients). Atoll sign that denotes organization process of the disease and even secondary fibrosing changes were also found (each in $10 \%$ of patients) (Fig. 2). Even the curvilinear bands with subpleural sparing, that denote healing process, were found in $3.3 \%$ of patients.

\section{Impact of HRCT findings on clinical decision}

The abovementioned HRCT results obviously impacted the clinical decision, as detailed in Table 2 . Modified or new clinical decision was obvious in 44/ 60 patients (73.3\%). Significant relation between HRCT positive findings among asymptomatic initial screened COVID-19 patients and clinical decision for these patients was statistically proven in Table 3 with $P$ value $<0.00001$.

Home isolation and medical treatment were the modified clinical decision, instead of uncontrolled release, for $26 / 42$ patients (62\%) who had negative PCR swab tests' results before HRCT. Repeating PCR tests was requested for them and PCR proved positive 2-4 days later. Among those 42 patients, 12 patients were health care providers and had to stop their duty immediately. Home isolation or isolated hospitalization instead of routine ward admission was the modified clinical decision for three and 15 patients respectively (Fig. 3).

Cautious surgical interference using full personal protective equipment (PPE) was carried out in five urgent surgeries instead of routine infection control measures. Delaying a scheduled chemotherapy cycle was decided for two patients. Delaying an elective interventional procedure was also decided for one patient. Strict infection control measures were requested for the radiology unit, which was visited by nine COVID-19 patients (Fig. 4).

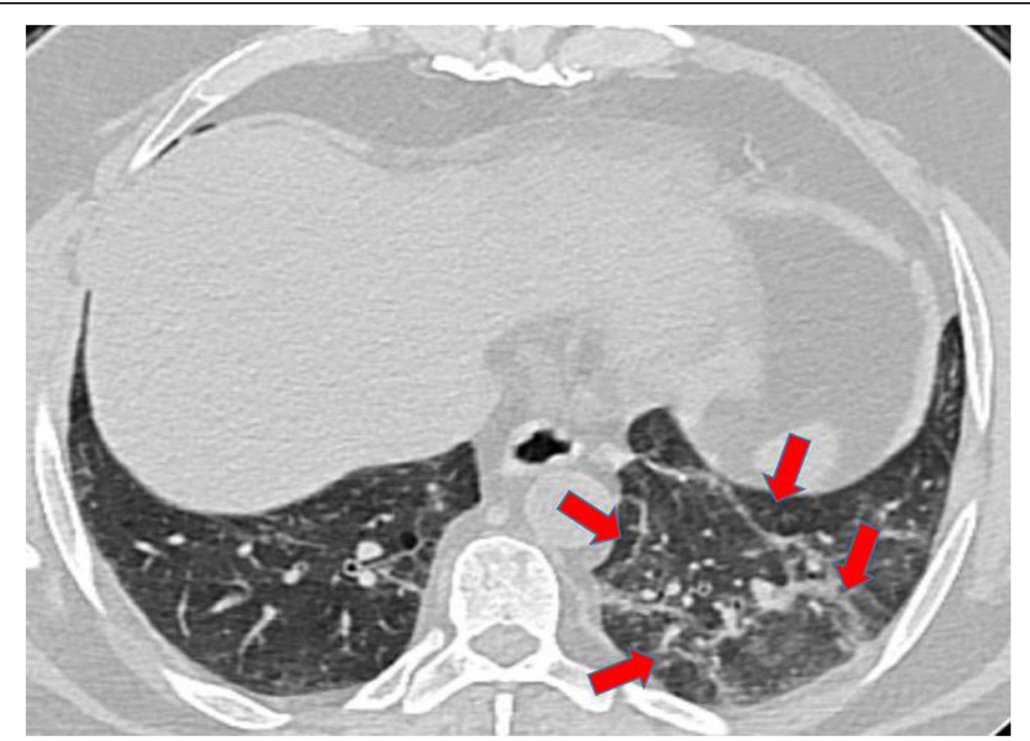

Fig. 2 A 52-year-old male patient who had positive contact history with recently proved COVID-19 patient and was completely asymptomatic: Axial HRCT chest lung window showed left lower lobar patchy GGOs with secondary fibrosing changes (red arrows). Clinical decision was home isolation, medical treatment, and PCR testing. Positive PCR result for COVID-19 was proved later 
Table 2 Classification of the included patients according to clinical situation and impact on clinical decision after HRCT results

\begin{tabular}{|c|c|c|c|c|c|}
\hline \multirow{2}{*}{$\begin{array}{l}\text { Group of } \\
\text { patients: } \\
\text { Asymptomatic } \\
\text { (Initially } \\
\text { screened) }\end{array}$} & \multicolumn{2}{|c|}{ Included patients: } & \multirow{2}{*}{$\begin{array}{l}\text { No } \\
30 / 60 \text { patients (including): } \\
\text { - First degree relatives (17). } \\
\text { - Work colleagues (13). } \\
\text { * N.B: 19/30 patients (63\%) } \\
\text { had negative prior first PCR } \\
\text { results. }\end{array}$} & \multirow{2}{*}{\begin{tabular}{l|}
$\%$ \\
$50 \%$ \\
$28.4 \%$ \\
$21.6 \%$ \\
$31.7 \%$
\end{tabular}} & \multirow{2}{*}{$\begin{array}{l}\text { Clinical decision changes: } \\
\text { Home isolation, medical treatment and PCR } \\
\text { testing instead for uncontrolled release. } \\
\text { (Repeating PCR for those } 19 \text { patients who } \\
\text { showed initial negative prior PCR swab tests' } \\
\text { results } \rightarrow \text { Proved positive later). }\end{array}$} \\
\hline & [1] & $\begin{array}{l}\text { People with positive contact history } \\
\text { with proved COVID-19 patients: }\end{array}$ & & & \\
\hline & [2] & $\begin{array}{l}\text { Health care providers with positive } \\
\text { contact history with proved COVID- } \\
19 \text { patients: }\end{array}$ & $\begin{array}{l}12 / 60 \text { patients (including): } \\
-7 \text { doctors } \\
-5 \text { nurses. } \\
\text { * N.B: } 7 / 12 \text { patients ( } 58.3 \% \text { ) } \\
\text { had negative prior first PCR } \\
\text { results. }\end{array}$ & $\begin{array}{l}20 \% \\
11.7 \% \\
8.3 \% \\
11.7 \%\end{array}$ & $\begin{array}{l}\text { Home isolation, medical treatment and PCR } \\
\text { testing instead of continuing providing health } \\
\text { service. (Repeating PCR for those } 7 \text { patients } \\
\text { who showed negative prior PCR swab tests' } \\
\text { results } \rightarrow \text { Proved positive later). }\end{array}$ \\
\hline & [3] & $\begin{array}{l}\text { Dialysis unit: Chest HCRT screening } \\
\text { before admission for dialysis. }\end{array}$ & $\begin{array}{l}4 / 60 \text { patients known with } \\
\text { end stage renal disease } \\
\text { (ESRD) }\end{array}$ & $6.7 \%$ & $\begin{array}{l}\text { PCR testing, isolated hospitalization and isolated } \\
\text { dialysis. }\end{array}$ \\
\hline & [4] & $\begin{array}{l}\text { Oncology unit: } \text { Chest } \mathrm{HRCT} \\
\text { screening before admission for } \\
\text { receiving chemotherapy. }\end{array}$ & $\begin{array}{l}\text { 2/60 patients (including): } \\
\text { - Metastasizing colon cancer. } \\
\text { - Breast cancer. }\end{array}$ & $3.3 \%$ & $\begin{array}{l}\text { PCR testing, isolated hospitalization and delay of } \\
\text { chemotherapy cycles. }\end{array}$ \\
\hline & [5] & $\begin{array}{l}\text { Emergency unit: Chest HRCT } \\
\text { screening before surgery planning. }\end{array}$ & $\begin{array}{l}\text { 2/60 patients (including): } \\
\text { - RTA. } \\
\text { - Abdominal exploration. }\end{array}$ & $3.3 \%$ & $\begin{array}{l}\text { * PCR testing and isolated hospitalization with for } \\
\text { the patients. } \\
\text { * Full PPE order for the surgery stuff. }\end{array}$ \\
\hline & [6] & $\begin{array}{l}\text { Intervention unit: Chest HRCT } \\
\text { screening before interventional } \\
\text { procedure. }\end{array}$ & $\begin{array}{l}\text { 1/60 patient asked for } \mathrm{CT} \\
\text { guided biopsy }\end{array}$ & $1.7 \%$ & $\begin{array}{l}\text { * PCR testing, isolated hospitalization, and } \\
\text { delaying biopsy appointment. }\end{array}$ \\
\hline & [7] & $\begin{array}{l}\text { Radiology unit: Chest HRCT } \\
\text { screening during or before } \\
\text { performing extra-thoracic } \\
\text { radiological investigation. }\end{array}$ & $\begin{array}{l}\text { 9/60 patients (including): } \\
\text { - CT enterocolonography (5). } \\
\text { - Urgent CT abdomen (3). } \\
\text { - Dorsal spine MRI as } \\
\text { metastatic workup for } \\
\text { cancer prostate (1). }\end{array}$ & $\begin{array}{l}15 \% \\
8.3 \% \\
5 \% \\
1.7 \%\end{array}$ & $\begin{array}{l}\text { * Strict infection control measures for CT and MRI } \\
\text { machines. } \\
\text { * PCR testing then home isolation and isolated } \\
\text { hospitalization for } 3 \text { and } 6 \text { patients respectively. } \\
\text { * Full PPE instructions for the surgery stuff } \\
\text { required for the three urgent cases. }\end{array}$ \\
\hline $\begin{array}{l}\text { Asymptomatic } \\
\text { (Recovered) }\end{array}$ & \multicolumn{2}{|c|}{$\begin{array}{l}\text { Follow up CT after two consecutive } \\
\text { negative PCR results for previous proved } \\
\text { COVID-19 patients. }\end{array}$} & $\begin{array}{l}60 \text { Patients } \\
\text { * All had unremarkable } \\
\text { laboratory tests and normal } \\
\mathrm{O}_{2} \text { sat levels. }\end{array}$ & $100 \%$ & $\begin{array}{l}\text { * Whatever the unexpected CT findings or lesions } \\
\text { size, clinical decision remain unchanged; no need } \\
\text { for re-isolation or re-hospitalization. } \\
\text { * Steroids were prescribed to speed lung recovery. } \\
\text { * Long term follow up for lung fibrosis was } \\
\text { advised. }\end{array}$ \\
\hline
\end{tabular}

\section{Regarding the asymptomatic recovered patients Residual HRCT findings (2-4 weeks after announcement of patient recovery by two consecutive negative PCR swab tests)}

Expected simple GGOs were found only in 12/60 (20\% of patients) while $40 \%$ of patients showed unexpected persistent curvilinear fibro-consolidative changes and also fibrosis on top of GGOs was found in $20 / 60$ (33.3\% of patients) (Fig. 5). One patient had persistent encysted hydro-pneumo-thorax for a whole month after announcing recovery (Fig. 6). One patient expressed traction bronchiectatic changes sequel to the lung fibrosis.

Small-sized residual lesions (less than $3 \mathrm{~cm}$ ) were only found in 10/60 (16.7\% of patients) while unexpected large lesions $(>3 \mathrm{~cm})$ were found in $70 \%$ of patients. Moreover, near $50 \%$ of lung involvement was found in $10 \%$ of patients (Fig. 7).

Table 3 Statistical analysis of significance of HRCT positive findings among asymptomatic initially screened COVID-19 patients on clinical decision

\begin{tabular}{llll}
\hline Positive HRCT initially screened patients & Clinical decision changed & Clinical decision unchanged & Total \\
\hline Initial (1st) PCR positive & $15(22.7)$ & $16(8.3)$ & $\mathbf{3 1}$ \\
Initial (1st) PCR negative & $29(21.3)$ & $0(7.7)$ & $\mathbf{2 9}$ \\
Total & $\mathbf{4 4}$ & $\mathbf{1 6}$ & $\mathbf{6 0}$ \\
\hline
\end{tabular}

${ }^{*}$ Chi-square value $(20.4)$ and $P$ value $(<0.00001)$. As $P$ value $(<0.05)$ is considered significant $\rightarrow$ so there is significant relation between HRCT positive findings among asymptomatic initial screened COVID-19 patients and clinical decision for these patients

* This footnote is the consequent value and interpretation of the given values in above-mentioned table 

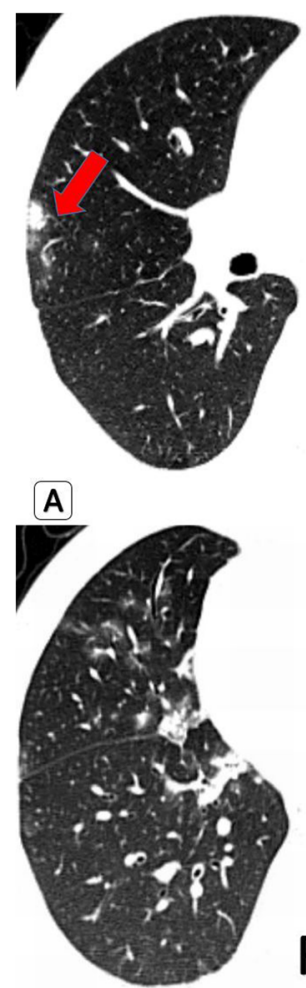

C

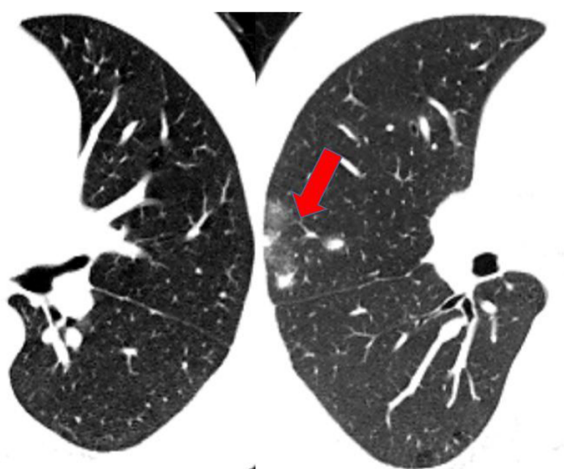

B

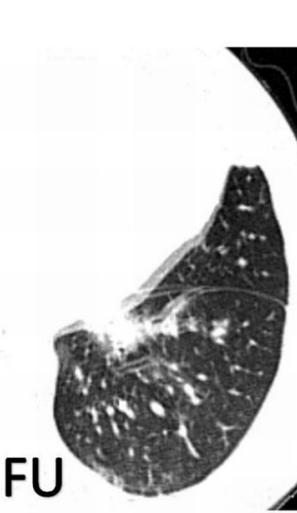

FU

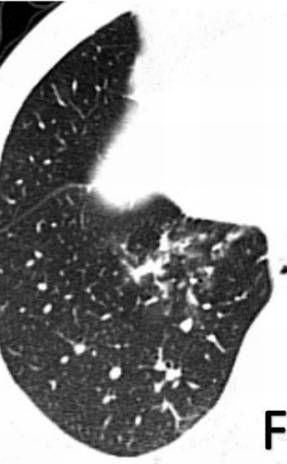

D

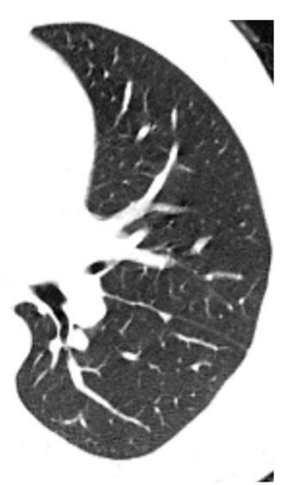

Fig. 3 A 33-year-male patient with SLE and ESRD who was completely asymptomatic however underwent screening HRCT scan prior to hospital admission for dialysis. a and $\mathbf{b}$ Axial HRCT of chest (lung window) shows initial presentation by unilateral right upper peripheral sub-pleural four solid nodules with GG "halo sign" (red arrows). They were conflicted as either COVID-19-related or SLE-related nodules. Isolated hospitalization, PCR testing and special isolated unit dialysis was the clinical decision. $\mathbf{c}$ and $\mathbf{d}$ Follow-up study for the patient 3 days later, he was also still completely asymptomatic: Axial HRCT chest showed de novo multiple bilateral GGO patches and left basal linear consolidation. PCR test for COVID19 was carried out and proved positive

\section{Impact of HRCT findings on clinical decision}

All recovered patients in this study had unremarkable laboratory tests and normal range of $\mathrm{O}_{2}$ saturation (95-100\% $\mathrm{O}_{2}$ Sat/RA), even those patients with secondary fibrotic changes $\left(95-96 \% \mathrm{O}_{2}\right.$ Sat/RA). Consequently, the clinical decision remained unchanged with no need for re-isolation or re-hospitalization whatever the prolonged and even unexpected residual CT findings. However, steroids were prescribed for all patients. Also, long term follow-up was recommended to those patients who had persistent secondary fibrosing changes to evaluate its effect on lung function and rule out the possibility for developing secondary interstitial lung fibrosis.

\section{Discussion}

This study surveyed the different HRCT findings among the asymptomatic and recovered patients proved for COVID-19, also recorded the unexpected results, and documented their impact on the clinical decision.
Regarding the asymptomatic patients with positive initial HRCT screening

Bilateral lung involvement was predominant in this study (70\%) conversely to Meng $\mathrm{H}$ et al. [9] who found unilateral lesions predominant in $58.6 \%$ of their patient, still the current study agreed with them regarding the prevalence of multiple lesions (more than 3 ) in $60 \%$ of patients. Consolidative changes mixed with GGOs were strikingly more than that noticed by Meng $\mathrm{H}$ et al. [9] (23.3\% compared to $5.2 \%)$ and unexpectedly disagreeing with $\mathrm{Hu} \mathrm{Z}$ et al. [10], Youssef I et al. [11], and Chang MC et al. [12] who found only pure GGOs (100\%) without any consolidative changes. "Crazy paving pattern" was depicted in $10 \%$ of patients, similar to Meng $\mathrm{H}$ et al. [9]. This may be explained by a higher viral load or different viral strains yielding unexpected more pathology despite being asymptomatic. Further researches may be needed for explanation of this notice.

These positive HRCT findings in asymptomatic initially screened patients had a significant impact on the 


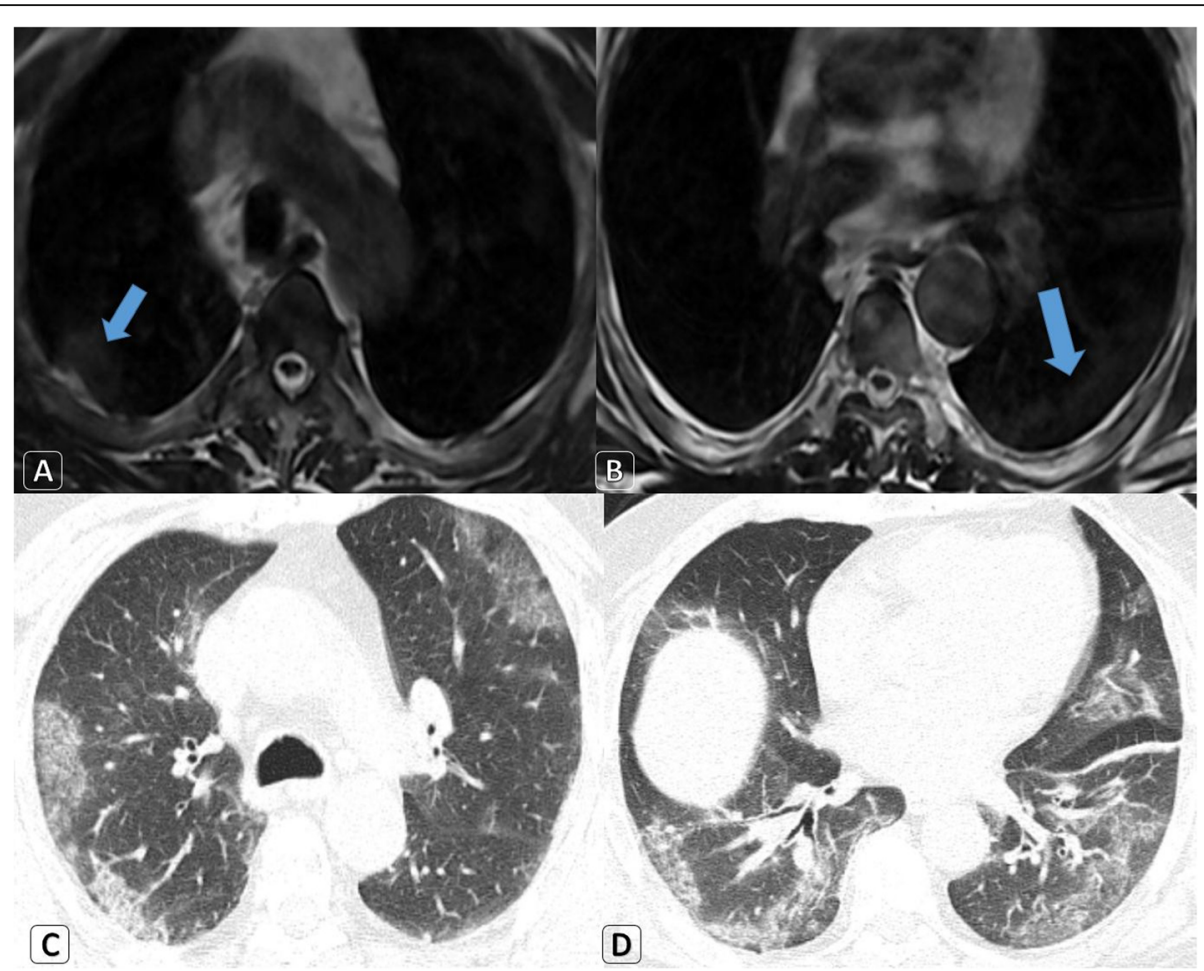

Fig. 4 A 58-year-old male patient with history of prostatic cancer. He had a visit to the radiology unit to do a whole spine MRI because of back pain. $\mathbf{a}-\mathbf{b}$ Dorsal spine MRI using high standard infection control measures revealed: axial T2WI showed the same patches with minimal overlying pleural reaction (blue arrows). c-d Screening axial chest HRCT lung window revealed bilateral large peripheral located ground-glass opacities mixed with consolidative changes. Clinical decision was isolated hospitalization, medical treatment, and PCR testing. Positive PCR result for COVID-19 was proved later

clinical decision as statistically proved $(P$ value $<0.0001)$ especially among those 29 patients who had initial prior negative PCR swab tests. Modified or new clinical decisions have been made as previously detailed in Table 2 in order to contain infection spread and to protect other patients and health care providers.

Based on the variable timing of positive PCR results among current asymptomatic initially screened patients, this study agreed with $\mathrm{Ai} \mathrm{T}$ et al. [13] that $\mathrm{CT}$ is a better tool than PCR in detection of COVID-19.

\section{Regarding the asymptomatic recovered patients}

During COVID-19 disease recovery and healing process, the consolidative changes in the current study were less than that found in Pan F et al. [14] (40\% compared to $75 \%)$. Gradual disappearance of these consolidative

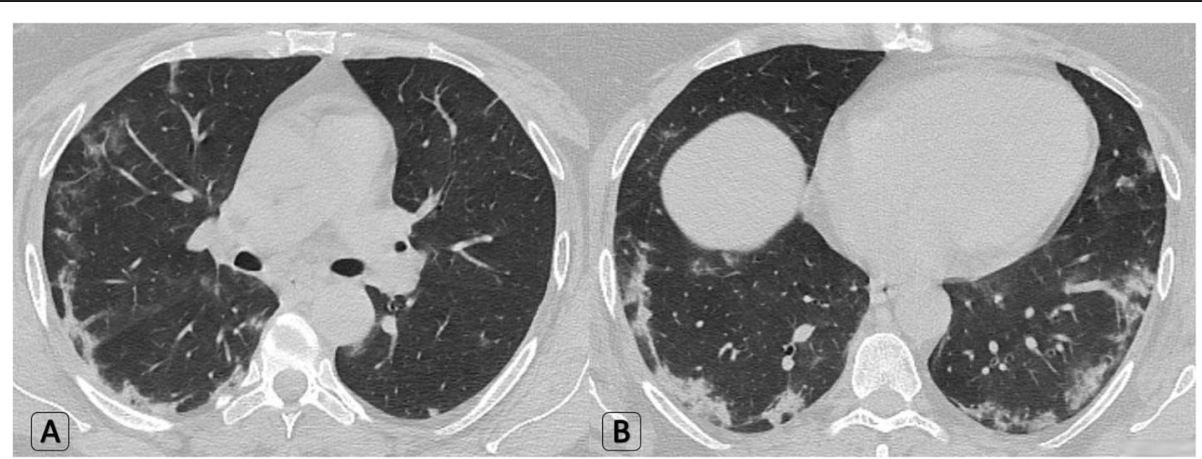

Fig. 5 A 42-year-old male patient known for COVID-19: Follow-up HRCT scans performed 2 weeks after announcing recovery. Patient was completely asymptomatic. $\mathrm{O}_{2}$ saturation $=97 \%$. Unremarkable laboratory results. $\mathbf{a}$-b Axial HRCT lung window showed residual bilateral sub-pleural curvilinear fibro-consolidative patches. Clinical decision was no need for re-isolation or re-hospitalization 


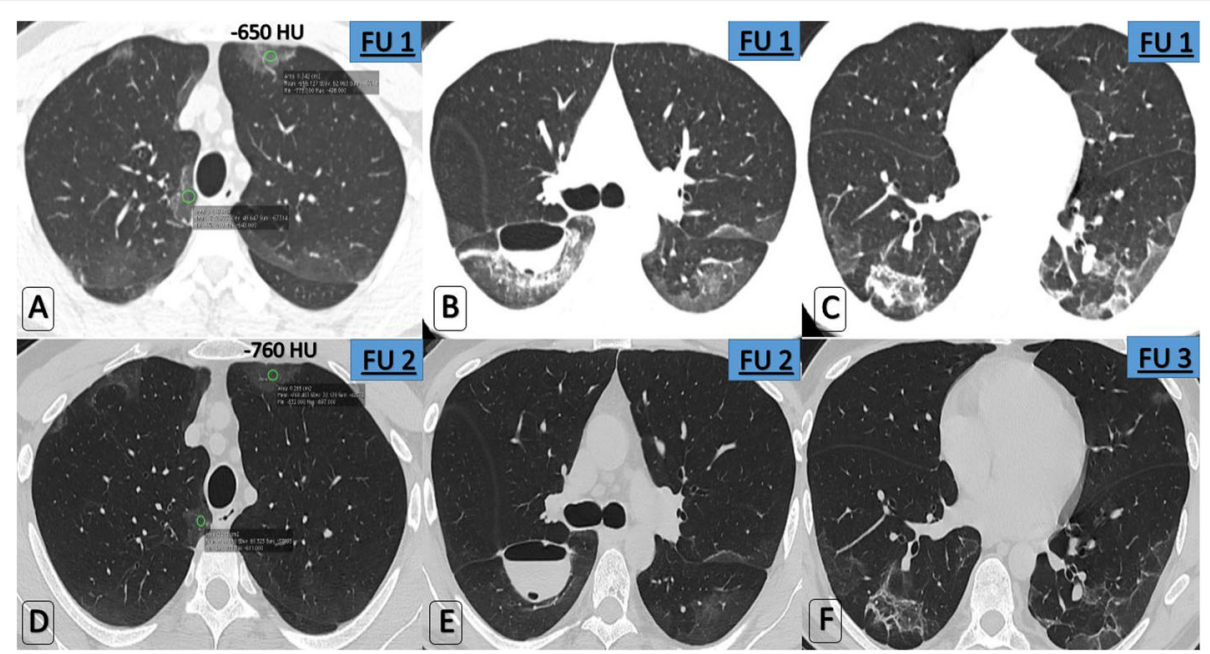

Fig. 6 Serial follow-up for a completely asymptomatic recovered 44-year-male patient proved with COVID-19. a, b, c First follow-up study edited 4 days after two consecutive negative tests' results announcing recovery. Axial HRCT chest-lung window; (a) higher GG attenuation (-650 HU), (b) process was complicated by encysted fissural hydro-pneumothorax surrounded by dense GGO and consolidative changes, (c) Peripheral dense organization is noted "Atoll sign." $\mathbf{d}$, e, $\mathbf{f}$ Next follow-up study edited 24 days later with axial HRCT chest-lung window; (d) GGO is approximating normal lung parenchyma $(-760 \mathrm{HU})$, (e) Near-total resolution of the dense $\mathrm{GGO}$ and consolidations surrounding the encysted fissural collection which retained the same size, however, noticed increased fluid component and decreased internal air, (f) disappearance of the "Atoll sign" and lower GGO values. Laboratory tests were unremarkable and $\mathrm{O}_{2}$ saturation in room air was $96 \%$. Clinical decision remains unchanged: No need for re-isolation or re-hospitalization

lesions and replacement by GGOs was the main followup sequel in the current study. These GGOs furtherly dropped in HU attenuation till approximating normal lung parenchymal attenuation. This matches the fourstep pathway for COVID-19 pneumonia recovery that was described by Pan F et al. [14]; however, in the current study, secondary fibrosis on top of GGOs was strikingly depicted in $33.3 \%$ of patients and even one patient expressed secondary bronchiectatic changes on top. This was not depicted at all by Pan F et al. [14]. The persistence of fibrosis was weird and concerned delayed persistent lung impact. Further long-term researches are advised for this notice.

Agreeing with Sun $\mathrm{R}$ et al. [15] who stated that pneumothorax could be one of COVID-19 infection outcomes, one patient showed persistent encysted fissural hydro-pneumothorax for a whole month after announcing recovery.

These positive HRCT findings in asymptomatic recovered patients did not change the current clinical decision whatever their grade or delayed persistence. No need for re-isolation or re-hospitalization was kept as the same

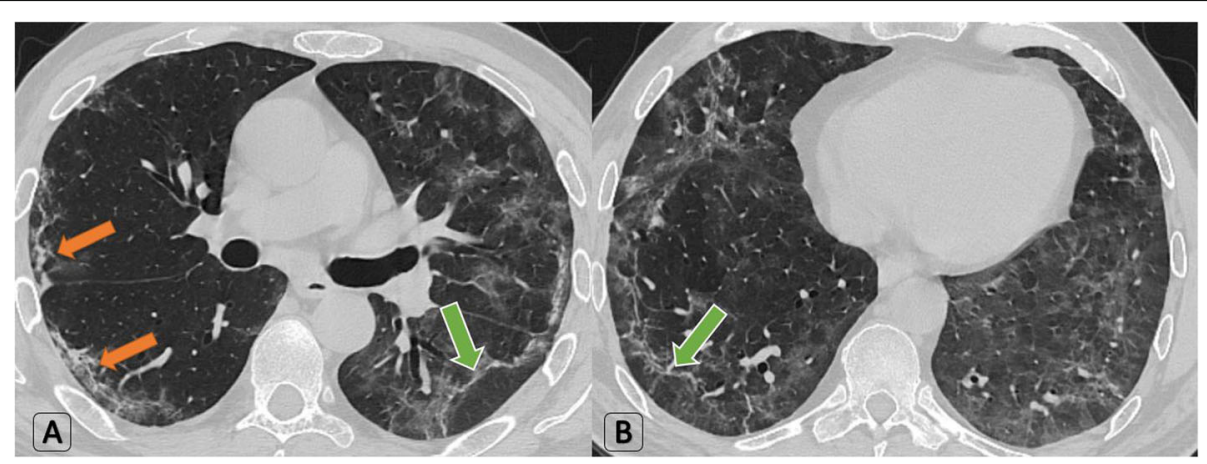

Fig. 7 A 37-year-old male patient known for COVID-19: Follow-up HRCT scans performed 18 days after announcing recovery. Patient is completely asymptomatic. $\mathrm{O}_{2}$ saturation $=95 \%$. Unremarkable laboratory results. $\mathbf{a}$-b Axial HRCT lung window showed residual bilateral large GGOs (approximating $50 \%$ of lobar volume), atoll sign (green arrows), and curvilinear fibrotic bands (orange arrows). Clinical decision was no need for re-isolation or re-hospitalization 
decision in all recovered patients. This was explained by the fact of "radiological lag," which was previously stated for pneumonia recovery by Bruns AH et al. [16] and described that clinical recovery always precedes radiological recovery. This was also enforced by the unremarkable laboratory tests and normal $\mathrm{O}_{2}$ saturation levels that were observed among these recovered patients. Steroids were prescribed for these patients to speed lung recovery. Long-term follow-up was recommended also to those patients with persistent secondary fibrosing changes to rule out permanent impact on lung functions or possibility for developing secondary interstitial lung fibrosis.

This study has the advantage for tracing the impact on clinical decision not only surveying CT features but also prolonged follow-up for recovered patient; however, it is limited by the small number of patients and lack of further knowledge about the further clinical outcome for those asymptomatic patients after the end of the isolation period.

\section{Conclusion}

HRCT findings among asymptomatic and recovered COVID-19 patients can be unexpected and can definitely impact the clinical decision.

\section{Abbreviations}

COVID 19: Coronavirus disease 2019; GGOs: Ground-glass opacities; HRCT: High-resolution computed tomography; RT-PCR: Reverse transcriptionpolymerase chain reaction

\section{Acknowledgements}

The authors would like to acknowledge Dr. Engy El-Kady, MD for her effort in data collection and proofreading the manuscript.

\section{Authors' contributions}

AS (the corresponding author) is responsible for ensuring that the descriptions are accurate and agreed by all authors. AS, MS, and $\mathrm{HH}$ had made substantial contributions to all of the following: (1) the conception and design of the radiological work, (2) the acquisition, analysis, and interpretation of radiological data, (3) drafting the work and revising it. Al had made substantial contributions to (1) acquisition, analysis, and interpretation of clinico-laboratory data, and (2) drafting the work and revising it. All authors approved the submitted version and revision. All authors have agreed both to be personally accountable for the author's own contributions and to ensure that questions related to the accuracy or integrity of any part of the work, even ones in which the author was not personally involved, are appropriately investigated, resolved, and the resolution documented in the literature.

\section{Funding}

None (authors personal contribution).

\section{Availability of data and materials}

The datasets used and/or analyzed during the current study are available from the corresponding author on reasonable request.

\section{Ethics approval and consent to participate}

The medical ethics were considered and respected. The study was approved by the Institutional Ethics Committee in the Faculty of Medicine, Alexandria University [IRB No: (00012098), FWA No: (00018699), Serial No: (0304694)]. Patient consent was waived in this retrospective observational study by the
Research Ethics Board, assuring respect of both patient and medical records confidentiality.

\section{Consent for publication}

Patient consent was waived in this retrospective observational study by the Research Ethics Board, assuring respect of both patient and medical records confidentiality.

\section{Competing interests \\ None}

\section{Author details}

${ }^{1}$ Department of Radiodiagnosis and Intervention, Faculty of Medicine, University of Alexandria, 17 Champollion Street, El-Messalah, Al-Kartoom Square, Al-Azareta, Alexandria 21526, Egypt. ${ }^{2}$ Department of Radiodiagnosis and Intervention, National Liver Institute, University of Menoufia, Shibin El Kom, Egypt. ${ }^{3}$ Department of Chest Diseases, Faculty of Medicine, University of Alexandria, Alexandria, Egypt.

Received: 23 September 2020 Accepted: 9 November 2020

Published online: 01 December 2020

\section{References}

1. Zhu N, Zhang D, Wang W et al (2020) A novel coronavirus from patients with pneumonia in China, 2019. N Engl J Med 382:727-733. https://doi.org/ 10.1056/NEJMoa2001017

2. Jebril N (2020) World Health Organization declared a pandemic public health menace: a systematic review of the coronavirus disease 2019 "COVID-19", up to 26th March 2020. Int J Psychosoc Rehabil 24(9):9160 9166. https://doi.org/10.37200/IJPR/N2419/PR290311

3. Kim H, Hong H, Yoon SH (2020) Diagnostic performance of CT and reverse transcriptase-polymerase chain reaction for coronavirus disease 2019: a meta-analysis. Radiology 296:E145-E155. https://doi.org/10.1148/radiol. 2020201343

4. Chan JF, Yuan S, Kok KH et al (2020) A familial cluster of pneumonia associated with the 2019 novel coronavirus indicating person-to-person transmission: a study of a family cluster. Lancet 395(10223):514-523 https:// doi.org/10.1016/S0140-6736(20)30154-9

5. Hong H, Wang Y, Chung HT, Chen CJ (2020) Clinical characteristics of novel coronavirus disease 2019 (COVID-19) in newborns, infants and children. Pediatr Neonatol. 61(2):131-132. https://doi.org/10.1016/j.pedneo.2020.03.001

6. Singhal T (2020) A review of coronavirus disease-2019 (COVID-19). Indian J Pediatr. 87(4):281-286

7. Pan Y, Yu X, Du X et al (2020) Epidemiological and clinical characteristics of 26 asymptomatic SARS-CoV-2 carriers. J Infect Dis 221(12):1940-1947. https://doi.org/10.1093/infdis/jiaa205

8. Zheng C (2020) Time course of lung changes at chest $C T$ during recovery from coronavirus disease 2019 (COVID-19). Radiology 295:715-721 https:// doi.org/10.1148/radiol.2020200370

9. Meng $H$, Xiong $R$, He R et al (2020) CT imaging and clinical course of asymptomatic cases with COVID-19 pneumonia at admission in Wuhan, China. J Infect 81:e33-e39 https://doi.org/10.1016/j.jinf.2020.04.004

10. $\mathrm{Hu} \mathrm{Z}$, Song C, Xu C et al (2020) Clinical characteristics of 24 asymptomatic infections with COVID-19 screened among close contacts in Nanjing, China. Sci China Life Sci 63(5):706-711. https://doi.org/10. 1007/s11427-020-1661-4

11. Youssef I, Donahue B, Flyer M, Thompson S, Huang A, Gallant F (2020) Covert COVID-19: CBCT lung changes in an asymptomatic patient receiving radiotherapy. Adv Radiat Oncol 5(4):715-721. https://doi.org/10.1016/j.adro. 2020.04.029

12. Chang MC, Hur J, Park D (2020) Chest computed tomography findings in asymptomatic patients with COVID-19. Respiration 1:1-7 https://doi.org/10. 1101/2020.05.09.20096370

13. Ai T, Yang Z, Hou H et al (2020) Correlation of chest CT and RT-PCR testing in coronavirus disease 2019 (COVID-19) in China: a report of 1014 cases. Radiology 296:E32-E40 https://doi.org/10.1148/radiol.2020200642

14. Pan F, Ye T, Sun P et al (2020) Time course of lung changes on chest CT during recovery from 2019 novel coronavirus (COVID-19) pneumonia. Radiology 13:200370 https://doi.org/10.1148/radiol.2020200370 
15. Sun R, Liu H, Wang X (2020) Mediastinal emphysema, giant bulla, and pneumothorax developed during the course of COVID-19 pneumonia. Korean J Radiol 21(5):541-544. https://doi.org/10.3348/kjr.2020.0180

16. Bruns AH, Oosterheert JJ, El Moussaoui R, Opmeer BC, Hoepelman Al, Prins JM (2010) Pneumonia recovery; discrepancies in perspectives of the radiologist, physician and patient. J Gen Intern Med 25(3):203-206. https:/ doi.org/10.1007/s11606-009-1182-7

\section{Publisher's Note}

Springer Nature remains neutral with regard to jurisdictional claims in published maps and institutional affiliations.

Submit your manuscript to a SpringerOpen ${ }^{\mathcal{O}}$ journal and benefit from:

- Convenient online submission

Rigorous peer review

- Open access: articles freely available online

- High visibility within the field

- Retaining the copyright to your article

Submit your next manuscript at $\boldsymbol{\sim}$ springeropen.com 